AJChE 2019, Vol. 19, No. 1, $66-73$

\title{
Surface Treatment of Superabsorbent Polymer with Corn Starch for Improved Properties
}

\section{Ariel V. Melendres* \\ Lorraine A. Carrillo}

Department of Chemical Engineering, Technological Institute of the Philippines, 363 P. Casal St., Quiapo, Manila 1001, Philippines

*e-mail: ariel.melendres@tip.edu.ph

Samples of superabsorbent polymer (SAP) were treated with corn starch to modify absorption and permeability properties. The process was done by homogenously mixing the superabsorbent polymer particles with starch suspension using starch loading of 0.002- $0.20 \mathrm{~g}$ of starch per $\mathrm{g}$ of SAP. The resulting mixture was then dried at temperature of $150^{\circ} \mathrm{C}$. The absorption properties such as Free Swell Capacity (FSC) and Absorption Under Pressure (AUP) of treated SAP were determined at different starch loading using test solution of varying sodium chloride concentrations and compared with the untreated SAP. At starch loading of $0.04 \mathrm{~g} / \mathrm{g}$, AUP gave better results than untreated SAP. GLP of treated SAP gave significant improvement which is explained in terms of the controlled swelling of SAP particles and a more porous structure of the SAP gel layer that allows faster liquid flow rate.

Keywords: Absorption, Free Swell Capacity, Permeability, Superabsorbent Polymers, Starch

\section{INTRODUCTION}

Hydrogels that are commonly called superabsorbent polymers (SAP) are crosslinked three dimensional networks of hydrophilic polymer chains that are capable of holding large amount of water due to their hydrophilic structure (Montesanoa et al. 2015, Ahmed 2015). SAPs are hydrophilic due to the presence of functional groups such as hydroxyl ($\mathrm{OH})$ and carboxylic acid $(-\mathrm{COOH})$ in its structure. These class of polymers are manufactured by free radical polymerization of acrylate monomers with crosslinking agents (Buchholz \& Graham 1998, Kiatkamjornwong 2007). The use of cross linkers to high water absorbent copolymers of acrylic acid and acryl amide copolymers produced high water absorbency (Liu \& Rempel 1998). When SAP swelled, a three dimensional membrane-like structure is formed that cause this exceptional property to absorb large amount of water.

SAPs are widely used for hygienic applications such as baby diapers, incontinence products and feminine napkins (Mohammad et al. 2008). To cope up with this changing structure of the diaper, SAP needs to be modified to be able to meet the required qualities, (Smith et al. 2005). Surface cross linkers are used to improve the SAP gel toughness (Moini 
2015). Increased gel strength leads to an improved application of SAP in hygienic products, i.e., better flow rate and liquid distribution within absorbent core. Besides having higher permeability, surface crosslinking improves the absorption under pressure of the SAP. Permeability is a property of porous materials that quantifies the relative ease with which a transporting substance can pass through the material (Figura et al. 2007). The permeability of superabsorbent gel is related to its gel strength, i.e. how firm is the original shape of the particles when saturated with the test solution such as $0.9 \%$ sodium chloride solution. In actual application, the permeability of SAP is a measure of how rapidly liquid flows through mass of swollen particles. Depending on its rigidity, the gel provides porosity to the superabsorbent gel layer enabling the water to pass through.

Improving the absorption against pressure and the swelling rate of SAP had been reported in several papers (Azad \& Sandros 016, Jockushch et al. 2009), by the application of cross linkers or surface modifiers on the surface of SAP. Due to SAP poor biodegradability, ideas that support on using renewable resources as raw materials for these synthetic polymers are necessary on developing new superabsorbent polymer structures. Thus, corn starch, a biodegradable material is used as a surface modifier for this study. Starch is a carbohydrate polymer consisting of anhydroglucose units linked by $\alpha-d-(1,4)$ glucosidic bonds. It is used in a variety of industries including plastics, adhesives, paper, and pharmaceuticals (Manek et al. 2012).
Although, several studies on the use of chemically modified starch have been reported (Zdanowics et al., 2010, Lee et al. 2018), SAP performance and properties with corn starch as surface modifier has yet to be studied, hence this study explored this gap in research and described the new function of starch as surface modifier of SAP. Moreover, this paper presents the methodologies of starch coating on the surface of SAP, the improvements made on the important properties of SAP such as absorption and permeability, and the mechanism by which these improved properties were achieved.

\section{MATERIALS AND METHODS}

\section{Materials}

Superabsorbent polymer (SAP) that is commercially available was used for the experiments. The SAP was obtained tightly sealed to maintain the moisture below $5 \%$. Analytical grade sodium chloride was obtained from Ajax Finechem. Deionized water with conductivity of $<5 \mu \mathrm{S} / \mathrm{cm}$ was used in preparing sodium chloride solutions. Corn starch was obtained from Alyson's Chemicals.

\section{Methods}

\section{SAP Gel Layer Permeability}

$0.9 \mathrm{~g}$ of SAP particles with size range of $300-600 \mu \mathrm{m}$ are spread on the 100 mesh stainless steel screen fixed at the bottom of the $6.0 \mathrm{~cm}$ diameter acrylic cylinder and allowed to swell at $0.9 \%$ sodium chloride for one hour after which a piston weight of $21 \mathrm{~g} / \mathrm{cm}^{2}$ is placed inside and the height of the gel layer is measured with a caliper. The whole 
apparatus is placed on the frame support shown in Fig.1 and the position of the sodium chloride reservoir is adjusted to maintain the liquid height, $h$, inside the cylinder to $4 \mathrm{~cm}$. The weight of $0.9 \%$ sodium chloride passing through the gel layer of SAP is recorded every 5 seconds for 3 minutes and the permeability is determined from gel height and flow rate. The permeability, $K$, is calculated based on Darcy Law, in Eq. (1).

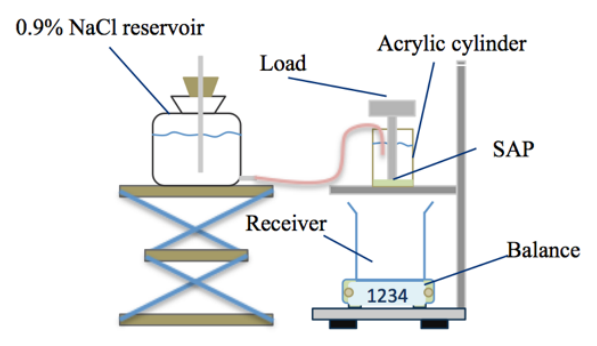

Fig. 1: Experimental set-up for GLP test.

$$
K=\frac{Q H \mu}{A \rho P}
$$

where $K$ is permeability in $\mathrm{cm}^{2}, Q$ is flow rate in $\mathrm{g} / \mathrm{s}, H$ is height of gel layer sample in $\mathrm{cm}, \mu$ is the liquid viscosity in MPa.s, $A$ is the cross sectional area in $\mathrm{cm}^{2}$ perpendicular to liquid flow, $\rho$ is the liquid density in $\mathrm{g} / \mathrm{cm}^{3}$, and $P$ is hydrostatic pressure in dynes $/ \mathrm{cm}^{2}$ which is calculated as $P=\rho g h$ where $g$ is gravitational acceleration in $\mathrm{cm} / \mathrm{s}^{2}$ and $h$ is the liquid height. The Gel Layer Permeability, GLP, in unit of Darcy is expressed from $K$ value using Eq. (2).

$$
G L P=\frac{K}{9.87 \times 10^{-9}}
$$

\section{Free Swell Capacity}

A specified weight of superabsorbent polymer is placed in the nonwoven bag. The bag containing the SAP sample is then soaked in the test solution of $\mathrm{NaCl}$ for 30 minutes. The excess liquid is allowed to drip for 10 minutes. The Free Swell Capacity, FSC, is evaluated by weighing the bag containing the SAP before and after soaking and is calculated using Eq. (3).

$$
F S C=\frac{m_{w}-m_{s}-m_{b}}{m_{s}}
$$

where $m_{w}$ is the mass of the wet bag containing the sample, $m_{s}$ is the mass of dry sample and $m_{b}$ is the mass of the wet blank bag.

\section{Absorption Under Pressure}

SAP particles are spread evenly on the 400 mesh stainless steel screen located at the bottom of the $60 \mathrm{~mm}$ diameter acrylic cylinder and a piston weight is inserted inside. Two weights of piston are used such as $21 \mathrm{~g} / \mathrm{cm}^{2}$ and $49 \mathrm{~g} / \mathrm{cm}^{2}$. A porous ceramic plate, with a filter paper on top of it, is placed on a $200 \mathrm{~mm}$ diameter petri dish containing the $0.9 \%$ sodium chloride solution. The cylinder apparatus is placed on top of the porous ceramic plate for one hour. The diagram for the set-up of AUP is shown in Fig. 2. The Absorption Under Pressure, AUP, is calculated using Eq. (4).

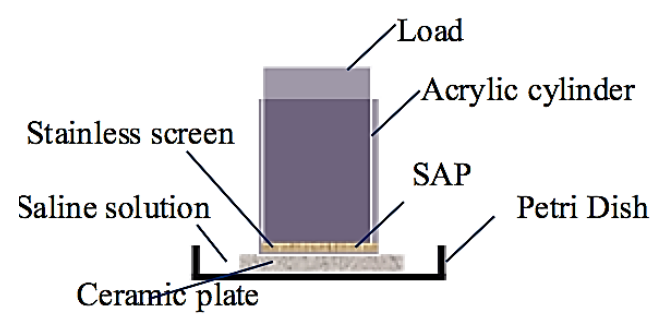

Fig. 2: The experimental set-up for AUP.

$$
A U P=\frac{m_{B}-m_{A}}{m_{s}}
$$


where $m_{A}$ is the mass of the apparatus before absorption, $m_{B}$ is the mass of the apparatus after absorption and $m_{s}$ is the mass of the sample.

\section{SAP Treatment with Starch}

$5-10 \%$ starch was suspended in pure water using magnetic stirrer until a homogenous mixture is obtained. While stirring the starch-water suspension, a specified amount was dropped onto the SAP and intensely mixed to obtain homogenous mixture with starch loading of $0.002-0.2 \mathrm{~g}$ starch per $\mathrm{g}$ SAP. The mixture was then dried at $150^{\circ} \mathrm{C}$. The resulting product was screened to obtain particles with size range of $300 \mu \mathrm{m}-600 \mu \mathrm{m}$.

\section{RESULTS AND DISCUSSION}

\section{SAP Before Treatment}

SAP was characterized for its properties in terms of FSC, AUP and GLP. Characterization of SAP showed the following properties at $0.9 \% \mathrm{w}$ sodium chloride solution: $F S C=65.13 \mathrm{~g} / \mathrm{g}, A U P$ at $21 \mathrm{~g} / \mathrm{cm}^{2}=23.23 \mathrm{~g} / \mathrm{g}, A U P$ at $49 \mathrm{~g} / \mathrm{cm}^{2}=$ $11.23 \mathrm{~g} / \mathrm{g}$. The permeability of SAP was evaluated and results of the mass of liquid passing through the SAP gel layer for every 5 seconds is shown in Fig. 3. The flow rate, $Q$, is evaluated from the slope of the line which has a value of $0.21 \mathrm{~g} / \mathrm{s}$. The height of the gel, $H$, is measured after one hour of swelling time which is equal to $1.45 \mathrm{~cm}$. The hydrostatic pressure $P$ is calculated as $P=\rho g h=1.0 \times 9.81 \times 4=$ 3924 dynes $/ \mathrm{cm}^{2}$. The area of the liquid perpendicular to the flow is $28.27 \mathrm{~cm}^{2}$. The value of $K$ is calculated from Eq. (1), while GLP is calculated using Eq. (2) giving a value of 2.78 Darcy. These values of FSC, AUP and GLP are typical of SAP properties as reported in other studies (Herfert et al. 2008, Jiang et al. 2016, Melendres et al. 2019).

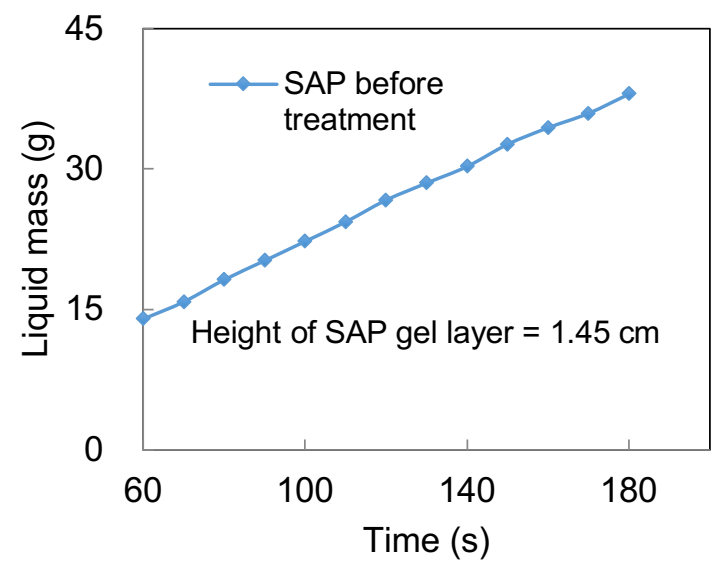

Fig. 3: Mass of liquid passing through gel layer vs time.

\section{SAP After Starch Treatment}

Fig. 4 describes the result of GLP tests for SAP after starch treatment showing the mass of liquid passing through gel layer for 180 seconds at different starch loadings, where the slope of the lines represent the flow rate, $Q$. SAP treated with starch loading of $0.2 \mathrm{~g} / \mathrm{g}$ gave the highest slope, with slope getting less steeper as the starch loading gets smaller. The values of $Q$ from Fig. 4 were substituted in Eq. (1) to solve for $K$ which is used to obtain GLP using Eq. (2). These values are plotted in Fig. 5 where GLP increases with increasing starch loading and flattened as starch loading is continually increased. SAP samples coated with starch gave higher $Q$, compared with untreated SAP (0 $\mathrm{g} / \mathrm{g}$ starch loading). These results confirmed the action of the corn starch coating on the surface structure of SAP. 


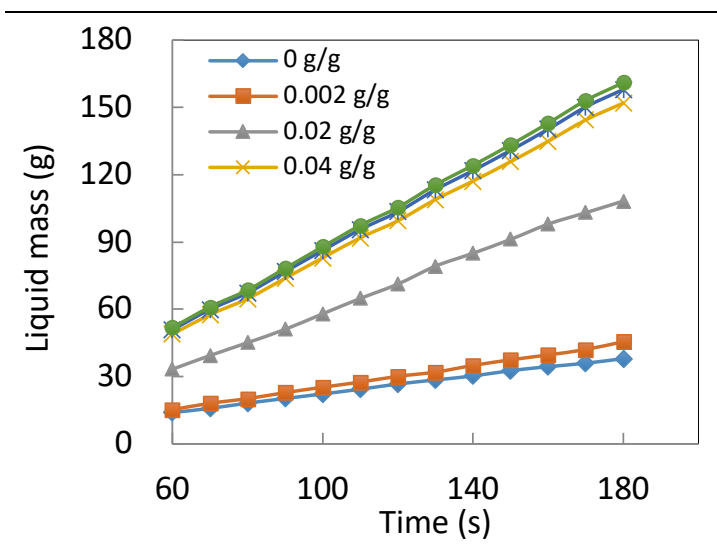

Fig. 4: Mass of Liquid vs. Time at different starch loading.

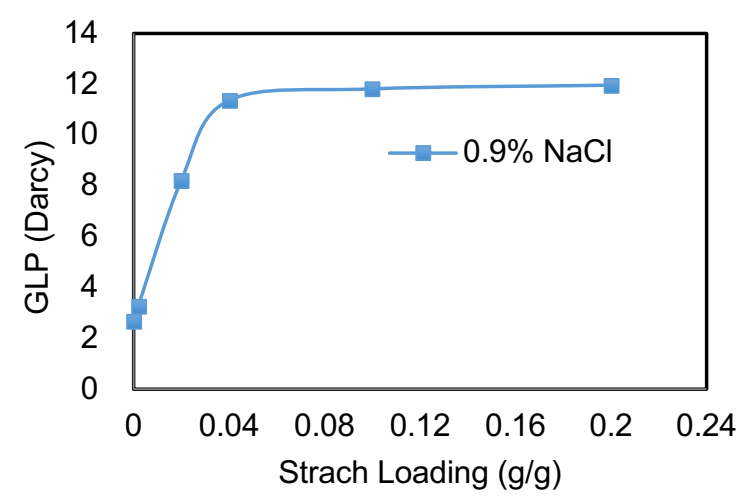

Fig. 5: Results of GLP at different starch loading.

\section{Free Swell Capacity}

The results of test for FSC using different concentrations of sodium chloride are shown in Fig. 6. The graph shows the absorption values of FSC decreasing with increasing concentration of sodium chloride for all the values of starch loading tested while the FSC decreases with increasing loading of starch signifying modified surface of SAP. The decrease in the FSC of SAP is a consequence of having a stiffer SAP gel resulting to controlled flow of water into the structure of SAP. Starch formed as coating agent by binding and modifying the surface of SAP. The interaction of SAP with starch is shown in Fig. 7 where the hydrogen bonding provides linkages between the ${ }^{-\mathrm{COO}^{-}}$and $-\mathrm{COOH}$ groups of the SAP chains and the hydroxyl and oxygen of the starch glucose molecules

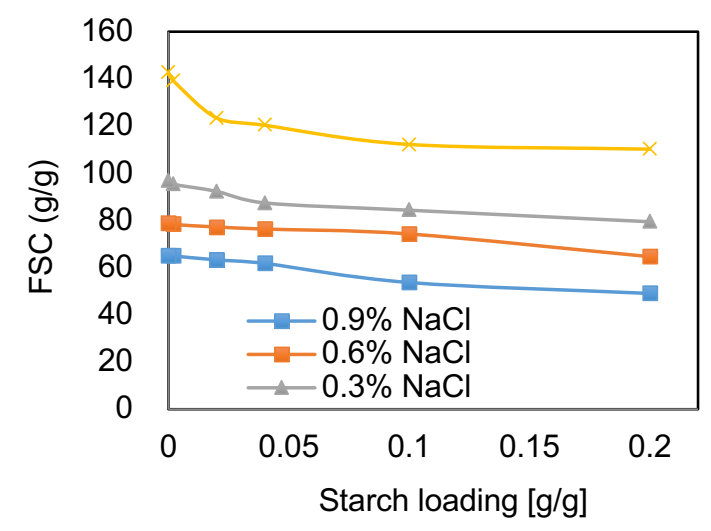

Fig. 6: Free Swell Capacity at different starch loading.

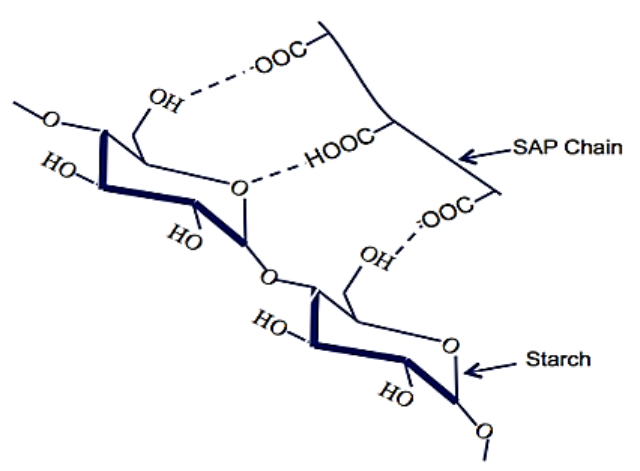

Fig. 7: Coating of starch with SAP surface. The dotted lines represents hydrogen bonding.

\section{Absorption Under Pressure}

The AUP of SAP were evaluated with load of $21 \mathrm{~g} / \mathrm{cm}^{2}$ and $49 \mathrm{~g} / \mathrm{cm}^{2}$ and the results are shown in Figs. 8-9 at different starch loading. Also shown in the Figs. 8-9 are the effect of sodium chloride in the absorption properties of SAP. For both 21 $\mathrm{g} / \mathrm{cm}^{2}$ and $49 \mathrm{~g} / \mathrm{cm}^{2}$, the absorption decreases as the concentration of sodium chloride is increased for all starch loading. 


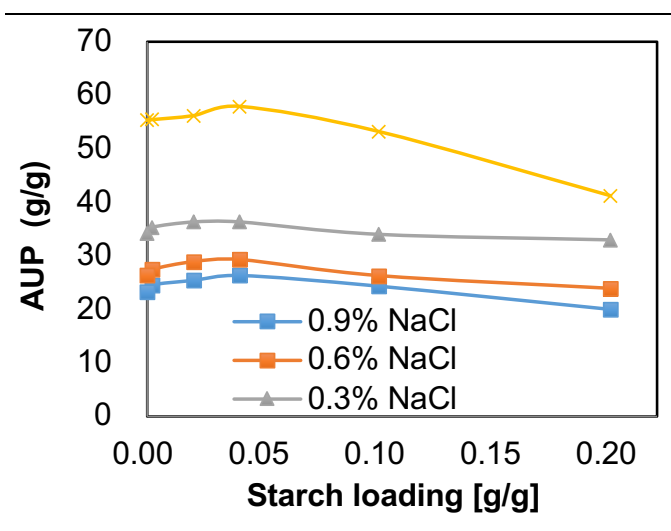

Fig. 8: $A U P$ at $21 \mathrm{~g} / \mathrm{cm}^{2}$ at different starch loading.

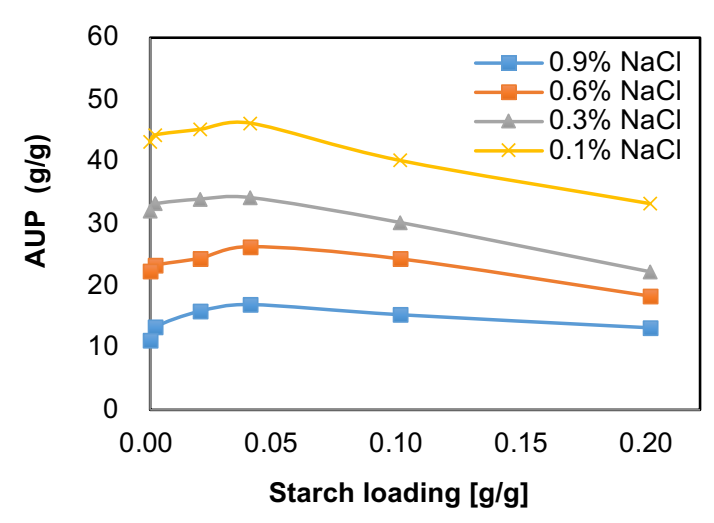

Fig. 9: $A U P$ at $49 \mathrm{~g} / \mathrm{cm}^{2}$ at different starch loading.

AUP at $21 \mathrm{~g} / \mathrm{cm}^{2}$ gave higher values than $49 \mathrm{~g} / \mathrm{cm}^{2}$. This is understandable that at higher pressure exerted on SAP, liquid absorption is reduced due to limited capacity, i.e. reduced volume, of the polymer network to hold the liquid. Also, $A U P$ increased with increased in starch loading and attained highest value of $A U P$ at $0.04 \mathrm{~g} / \mathrm{g}$ starch loading for both 21 $\mathrm{g} / \mathrm{cm}^{2}$ and $49 \mathrm{~g} / \mathrm{cm}^{2}$.

The difference in the absorption of water before and after treatment can be described in Fig. 10, showing untreated and treated SAP particles. The diagram shows the effect of the treatment on the flow of liquid into the SAP structure and on the SAP gel layer. The rate of liquid passing through depends on the porosity of the SAP gel layer.
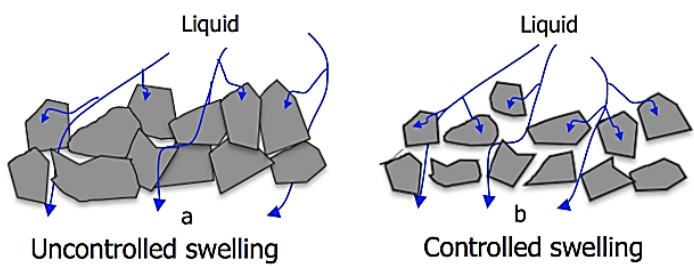

Fig. 10: Liquid flow through SAP gel layer (a) before treatment and (b) after treatment.

Starch-treated SAP particles protected their shapes during the swelling process causing controlled diffusion of water into the SAP structure and thus controlled swelling. This is in contrast to untreated SAP where water flows without control into the SAP structure causing uncontrolled swelling. Hence, while untreated SAP gave bigger SAP gel particles, the treated particles are smaller leading to a less dense packed gel layer and higher porosity as shown in Fig. 10. This resulted to a more permeable SAP gel layer as shown by the results of tests in Figs. 5-6 above-where treated SAP gave lower FSC but higher in GLP. Moreover, treated SAP has stronger gel particles resulting to higher absorbency under pressure, than untreated SAP as a result of coating protection (Mudiyanselage et al. 2008). This is also the reason why treated SAP has higher GLP than untreated one. The AUP values are higher at starch loading of $0.04 \mathrm{~g} / \mathrm{g}$ compared with untreated SAP particles. Lower values of AUP were obtained at $>0.04 \mathrm{~g} / \mathrm{g}$ starch loading due to lesser amount of water absorbed as the coating gets more thicker as shown in the Figs. 8-9. 


\section{CONCLUSION}

Superabsorbent polymers were surface treated with the use of corn starch for the purpose of modifying the absorption and permeability properties. SAP before treatment of starch gave FSC of $65.13 \mathrm{~g} / \mathrm{g}$, $A U P$ at $21 \mathrm{~g} / \mathrm{cm}^{2}$ and $49 \mathrm{~g} / \mathrm{cm}^{2}$ of 23.23 $\mathrm{g} / \mathrm{g}$ and $11.23 \mathrm{~g} / \mathrm{g}$ respectively and GLP of 2.78 Darcy using test solution of $0.9 \%$ sodium chloride solution. While the values FSC decreased, marked improvements were seen on the values of $A U P$ and GLP. The improvement in GLP at starch loading of $0.04 \mathrm{~g} / \mathrm{g}$ to a value of 11.37 Darcy is believed to be due to a more porous SAP gel layer. A firmer SAP gel was obtained after SAP treatment giving better AUP where the highest value at $21 \mathrm{~g} / \mathrm{cm}^{2}$ and at $49 \mathrm{~g} / \mathrm{cm}^{2}$ using test solution of $0.9 \%$ sodium chloride was attained at $0.04 \mathrm{~g} / \mathrm{g}$ starch loading.

\section{ACKNOWLEDGEMENT}

The authors would like to acknowledge the support given by Department of Science and Technology, Philippines.

\section{NOMENCLATURE}

$$
\begin{aligned}
& \text { FSC : Free Swell Capacity }[\mathrm{g} / \mathrm{g}] \\
& \text { AUP : Absorption Under Pressure }[\mathrm{g} / \mathrm{g}] \\
& \text { GLP : Gel Layer Permeability [Darcy] } \\
& m_{A} \text { : Mass of apparatus before } \\
& \text { absorption [g] } \\
& m_{B} \text { : Mass of apparatus after absorption } \\
& \text { [g] } \\
& m_{s} \quad: \quad \text { Mass of dry sample [g] } \\
& m_{w} \quad \text { : Mass of wet bag [g] } \\
& m_{b} \quad \text { : Mass of wet blank bag [g] } \\
& K \quad: \text { Permeability }\left[\mathrm{cm}^{2}\right]
\end{aligned}
$$

$\begin{array}{lll}Q & : & \text { Flow rate }[\mathrm{g} / \mathrm{s}] \\ H & : & \text { Gel layer height }[\mathrm{cm}] \\ h & : & \text { Liquid height }[\mathrm{cm}] \\ \mu & : & \text { Liquid viscosity }[\mathrm{MPa} . \mathrm{s}] \\ A & : & \text { Cross sectional area }\left[\mathrm{cm}^{2}\right] \\ \rho & : & \text { Liquid density }\left[\mathrm{g} / \mathrm{cm}^{3}\right] \\ P & : & \text { Hydrostatic pressure }\left[\text { dynes } / \mathrm{cm}^{2}\right]\end{array}$

\section{REFERENCES}

1. Ahmed, E.M., (2015). Hydrogel, Preparation, characterization, and applications: A review, Journal of Advanced Research, 6(2),105-121.

2. Azad, M.M., Sandros, M.G., (2016). Inert Addition and surface coating of superabsorbent polymer for improved physical properties, Journal of Applied Polymer Science, 133 (39).

3. Buchholz, F.L., Graham, A. T. (1998). Modern Superabsorbent Polymer Technology, Wiley-VCH, New York.

4. Figura, L.O., Teixeira, A.A. (2007). Food Physics. Physical Properties Measurement and Applications. Springer, Berlin

5. Herfert, N., Miatudila, M. K. and Mitchel, M.A. (2007). US Pat. 2008/0187755A1

6. Jiang, C., Cao, X. and Guo, L., (2016). Synthesis and swelling behavior of poly (acrylic acid-acryl amide-2acrylamido-2-methyl-propansulfonic acid) superabsorbent copolymer, J. of Petroleum Exploration and Production Technology. 7 (1), 69-75

7. Jockushch, S., Turro, N.J., Mitsukami, Y., Matsumoto, M., Iwamura, T., Lindner, T., Flohr, A., Massimo, G, (2009). Photoinduced surface crosslinking of superabsorbent polymer particles, 
Journal of Applied Polymer Science, 111 (5), 2163-2170.

8. Kiatkamjornwong, S., (2007). Superabsorbent Polymers and Superabsorbent Polymer Composites, ScienceAsia, 33(1), 39-43.

9. Lee, J., Park, S., Roh, H., Oh, S., Kim, S., Kim, M., Kim, D., Park, J., (2018). Preparation and Characterization of Superabsorbent Polymers Based on Starch Aldehydes and Carboxymethyl Cellulose, Polymers, 10 (6),605.

10. Liu, Z. S., Rempel, G.L., (1997). Preparation of superabsorbent polymers by crosslinking Acrylic Acid and Acrylamide Copolymers, Journal of Applied Polymer Science. 64 (7), 13451353.

11. Manek, R.V., Builders, P.F., Kolling, W.M., Emeje, M., Kunle O.O., (2012). Physicochemical and Binder Properties of Starch Obtained from Cyperus esculentus, AAPS PharmSciTech, 13 (2), 379-388.

12. Melendres, A., Antang J. A., Manacob, J., (2019). Investigation of Superabsorbent Polymer Absorbency at Reduced Chemical Potential of Water, MATEC Web of Conferences. 268, 04010

13. Mohammad, J., Zohuriaan-Mehr, M.J., Kabiri, K., (2008). Superabsorbent Polymer Materials: A review, Iranian Polymer Journal, 6, 451-477.

14. Moini, N., Kabiri, K., (2015). Effective parameters in surface cross-linking of acrylic-based water absorbent polymer particles using bisphenol $A$ diethylene glycidyl ether and cycloaliphatic diepoxide, Iran Polymer Journal, 24, 977-987.

15. Montesanoa, F.F, Parente, A., Santamaria, P., Sannino, A., Serio, F., (2015). Biodegradable Superabsorbent Hydrogel increases water retention properties of growing media and plant growth, Agriculture and Agricultural Science Procedia, 4, 451-458.

16. Mudiyanselage, T. K. and Neckers, D. C., Highly (2008), Absorbing Superabsorbent Polymer, Journal of Polymer Science A Polymer Chemistry, 46, 1357-1364.

17. Smith, S.J., Mcintosh, S., Bremus, $H_{\text {., }}$ Loeker, K. (2005). U.S. Pat. 2005/0096435 A1.

18. Zdanowicz, M., Schmidt, B., Spychaj, T., (2010). Starch graft copolymers as superabsorbent obtained via reactive extrusion processing, Pol. J. Chem. Technol., 12, 14-17. 